\section{Factoring in an impact}

\author{
Phil Wiffen
}

I recently met with a group of senior hospital clinical pharmacists to encourage them to publish and mentor others to do the same. Quite early on, the discussion turned to impact factors (IFs) from this knowledgeable group. Some 10 years or so ago I suspect that most hospital pharmacists didn't know about such things. Partly due to the evaluation of academia and linked to funding streams, this issue is now important. That source of useful knowledge 'Wikipedia' ${ }^{1}$ helpfully describes an IF as:

In a given year, the impact factor of a journal is the average number of citations received per paper published in that journal during the two preceding years. For example, if a journal has an impact factor of 3 in 2008, then its papers published in 2006 and 2007 received 3 citations each on average in 2008. The 2008 impact factor of a journal would be calculated as follows:

$\mathrm{A}=$ the number of times that articles published in that journal in 2006 and 2007 , were cited by articles in indexed journals during 2008.

$\mathrm{B}=$ the total number of "citable items" published by that journal in 2006 and 2007. ("Citable items" are usually

Correspondence to Professor Phil Wiffen, Pain Research Unit, Churchill Hospital, Old Rd, Oxford OX3 7LE, UK; phil.wiffen@ndcn.ox.ac.uk articles, reviews, proceedings, or notes; not editorials or letters to the editor.) 2008 impact factor $=\mathrm{A} / \mathrm{B}$.

These are calculated by Thomson Reuters ISI (Institute for Scientific Information) and published annually. Within medicine, the range of IFs is wide with the New England Journal of Medicine up at around 53, and the BMJ at 14 . The best pharmacy journals come in at around two with EJHP at 0.15 . Overall, there are 260 journals in the Pharmacology and Pharmacy category with the IF ranging from 0 to 29.

It is obvious that papers can only be cited if they can be discovered, so I am pleased to tell you that EJHP is now also indexed in CINAHL (Cumulative Index to Nursing and Allied Health Literature). This database of approaching 3 million records is not well known among pharmacists though it provides a good source of pharmacy-related material covering service provision and pharmacy management. The database is known to scientific librarians (useful allies), and contains a large section of nursing literature as well other clinical speciality material. This is a first step to seeking inclusion in larger medical databases. This issue contains a basic introduction to searching and using CINAHL.

IFs are one thing, but do they lead to making an impact? Part of my week is spent working on systematic reviews for the Cochrane Collaboration. The collaboration's product, 'The Cochrane Library', has an IF of just below 6. That said, there is regular criticism that Cochrane reviews are dense and a difficult read. They are often cited as they provide a distillation of evidence that informs practice and guidelines.

This journal needs contributions that make an impact on pharmacy practice, and we have seen many such papers over recent years. These can appear either as a research report following a piece of investigative work which may be about formulation, or could equally be about introduction of new services related to new opportunities or challenges or as 'wisdom' type papers. The place of wisdom is to describe where challenges have been met and the effects followed-up or evaluated. The idea is to give others a helping hand to develop or extend their own practice.

Impact and IFs are not mutually exclusive, we need both. My aim is to see the IFs rise while ensuring that this highquality scientific journal for hospital pharmacists is a vehicle for research and wisdom that improves practice in Europe and beyond.

\section{Competing interests None.}

Provenance and peer review Commissioned; internally peer reviewed.

To cite Wiffen P. Eur J Hosp Pharm 2013;20:145.

Eur J Hosp Pharm 2013;20:145.

doi:10.1136/ejhpharm-2013-000317

\section{REFERENCE}

1 http://en.wikipedia.org/wiki//mpact_factor (accessed Apr 2013). 